\title{
Foliar Application of Aviglycine Reduces Natural Flowering in Pineapple
}

\author{
Ching-San Kuan \\ Department of Horticulture, Chia-Yi Agricultural Experiment Station, \\ TARI,Chia-Yi, Taiwan, R.O.C.
}

Chih-Wen Yu

Department of Molecular Biotechnology, Da-Yeh University, Chang-Hua, Taiwan, R.O.C.

Mei-Li Lin and Hsin-Tszu Hsu

Department of Horticulture, Chia-Yi Agricultural Experiment Station, TARI, Chia-Yi, Taiwan, R.O.C.

Duane P. Bartholomew

Department of Tropical Plant and Soil Science, University of Hawaii, Manoa HI 96822

\section{Chin-Ho Lin ${ }^{1}$}

Department of Life Science, National Chung Hsing University, Taichung, Taiwan, R.O.C.

Additional index words. Ananas comosus, aviglycine, pineapple, natural flowering

\begin{abstract}
Natural flowering of pineapple is a serious problem for commercial growers of pineapple because it disrupts fruiting schedules, decreases harvesting efficiency and increases costs, and may reduce the percentage of marketable fruit. Aviglycine ([S]-trans2-amino-4-(2 aminoethoxy)-3-butenoic acid hydrochloride), an inhibitor of ethylene biosynthesis, was applied as a foliar spray to evaluate its potential to prevent natural flowering in 1-year-old 'Tainon 18' pineapple. Two experiments were conducted between 10 Oct. and 10 Apr. during the 2001-02 and 2002-03 production seasons. For the 2001-02 season, single or double applications of aviglycine at $100 \mathrm{mg} \mathrm{L}^{-1}$ had no significant effect on natural flowering. A double application of aviglycine at $500 \mathrm{mg} \mathrm{L}^{-1}$ first applied on 9 Nov. reduced flowering from $95.0 \%$ in the control to $51.3 \%$ when evaluated on 25 Feb. 2002. In the 2002- 03 production season, triple applications of aviglycine applied at 20 -day intervals beginning on 10 Nov. 2002 significantly reduced natural flowering when evaluated on 28 Mar. 2003. There was $95.8 \%$ flowering in the control, $64.6 \%$ with 250 and 375 $\mathrm{mg} \mathrm{L}^{-1}$ aviglycine, and $50 \%$ with $500 \mathrm{mg} \mathrm{L}^{-1}$ aviglycine. Aviglycine has the potential to partially control precocious flowering of pineapple, which will reduce crop losses associated with such flowering.
\end{abstract}

Pineapple (Ananas comosus [L.] Merr.) originated in South America, is a tropical fruit as it does not withstand frost, and is commonly planted within $30^{\circ} \mathrm{N}$ and $\mathrm{S}$ latitude. According to Gowing (1961) and Friend and Lydon (1979), pineapple is a quantitative but not an obligate short-day plant and low night temperature enhances the induction of reproductive development (natural induction) (Van Overbeek and Cruzado, 1948). Natural induction mainly occurs in the cooler winter months and the incidence is higher at subtropical latitudes where temperatures are cooler and winter daylengths are shorter (Bartholomew et al., 2003). Natural induction events within the cool season are thought to result from sudden drops in temperature associated with passing cold fronts. Natural induction is a serious prob-

Received for publication 1 Mar. 2004. Accepted for publication 29 June 2004.

${ }^{1}$ Corresponding author; e-mail chlin@mail.nchu. edu.tw. lem for pineapple growers because it makes it difficult for growers to schedule fruiting and increases harvesting costs or reduces yields, or both. Percentage natural induction varies from year to year and can range from $0 \%$ to $100 \%$ in any given year.

Forced induction of flowering (forcing) of pineapple is a well-established commercial practice that allows pineapple fruit to be harvested in most months of the year. Forcing also induces almost $100 \%$ of the plants and produces a sharp ripening peak, which keeps harvesting costs low. Plant sensitivity to forcing is highest during periods when natural induction normally occurs (Bartholomew et al., 2003) and sensitivity to forced and natural induction is determined by cultivar, plant size, nutrient and water stress and pest pressure, particularly nematodes. 'Smooth Cayenne' has low sensitivity while 'Singapore Spanish' and newer hybrids such as 73-114 (MD-2, Chan et al., 2003) and Tainon 18 (C.H. Lin, personal observation) have higher sensitivity. Cultivar differences in plant sensitivity appear to have the greatest influence on natural induction followed by weather events and cultural practices. The physiological interactions among all the above factors have not been adequately characterized so plant sensitivity and incidence of natural flowering are unpredictable.

Forced flower induction of pineapple is commonly done with ethylene or ethephon once some minimum plant size has been attained (Bartholomew et al., 2003). Fruit mass is highly correlated with plant mass so forcing is done only when plants are of sufficient size to produce fruit large enough to be of economic value. In Taiwan (22 to $26^{\circ} \mathrm{N}$ latitude), most forcing is done during September and October and the fruit is harvested from March to May of the following year. A disadvantage of this practice is that fruit are unavailable between September and February of the following year. However, if forcing of fully developed plants is delayed beyond October, they are highly susceptible to natural induction from late November until late March (C.H. Lin, personal observation). Natural induction during that time would reduce the number of plants available for forcing from March to July and limit the number of fruit that could be produced between September and February of the following year.

Control of natural flowering of pineapple has been a research and management objective for many years. The problem can be partially controlled by cultural practices that minimize stresses and promote rapid vegetative growth (Bartholomew et al., 2003). Gowing and Leeper (1960) showed that a low concentration of an auxin will force flowering of pineapple while higher concentrations inhibit it and more recently others have shown that foliar sprays of 2-(3-chlorophenoxy)-propionic acid reduced the percentage of natural induction of pineapple (Scott, 1993; Rebolledo-Martinez et al., 1997; Rebolledo et al., 2000). Regulatory issues may have prevented this work from continuing. Auxin-induced forcing is via auxin-stimulated ethylene (Burg and Burg, 1966) but the mechanism by which auxin inhibits natural induction is not known. Because forcing is accomplished with ethylene, it has been assumed that natural induction results from increased ethylene production or increased plant sensitivity to endogenously produced ethylene, or both. Control of natural induction is, therefore, viewed as a problem of inhibiting ethylene production or action. Aviglycine ([S]trans-2-amino-4-(2 aminoethoxy)-3-butenoic acid hydrochloride), marketed commercially as ReTain (Valent Biosciences Corp.), inhibits ethylene production in plants and is registered in the United States to improve fruit retention of apples and pears. The flowering physiology of ornamental bromeliads is similar to that of pineapple as these plants can be forced to flower with ethephon and flower naturally when subjected to physiological stress. Mekers et al. (1983) examined the extent of control of unwanted flowering of ornamental bromeliads by the ethylene production inhibitors aminooxyacetic acid, aviglycine, and silverthiosulfate and found aviglycine to be the most active compound at low concentration. 
Rapid conversion of pineapple plantings to sensitive cultivars prone to flower naturally in recent years has made control of natural flowering an urgent and economically important production issue and control is more critical where cultivars of high sensitivity to natural induction are grown at subtropical latitudes. The increased interest in controlling natural flowering coincides with the fairly recent availability of commercial quantities of aviglycine. The main objective of this research was to examine the potential of aviglycine to control precocious natural flowering of fieldgrown pineapple so the grower rather than nature could determine the date reproductive development is initiated.

\section{Material and Methods}

One year old field-grown Tainon 18 pineapple ( Ananas comosus [L.] Merr.) (a cross between 'Smooth Cayenne' and 'Smooth Cayenne' $\times$ 'Singapore' (female) has the cultivar name Osmanthus fragrance) plants were employed throughout this study. 'Tainon 18 was selected because it has a high percentage of natural induction, in some years reaching $100 \%$. Experiments were conducted during the 2001-02 and 2002-03 production seasons. In the 2001-02 season, the experi- ment was conducted on an experimental field of Taiwan Agricultural Research Institute's Chia Yi Experimental Station $\left(23^{\circ} \mathrm{N}\right.$ latitude). The aviglycine (ReTain) treatments were first applied on 19 Oct. 2001 and applications were last made on 20 Dec. 2001. Experience in Taiwan has shown that a sufficiently high percentage of natural induction would have occurred by that date to provide an adequate opportunity to assess the treatment effects. The treatment levels and dates of application are shown in Table 1. The experiment was terminated when the inflorescence number, expressed as a percentage, reached a plateau. The 2002-03 trial was conducted on a private pineapple farm 10 kilometers from the Chia Yi Experimental Station. The procedures for conducting the test and evaluating natural flowering were the same as in the 2001-02 season, except that higher concentrations of aviglycine were used and double and triple applications were made (Table 2).

In each season, treatments were arranged in a randomized complete block design with four replications. Plants per replication were 20 in 2001-02 and 12 in 2002-03. Control plants were sprayed to run-off with water containing 0.02\% Break-Thru (Goldschmidt Chemical Corp.), a nonionic surfactant. For the aviglycine treatments, a soluble powder containing $15 \%$ a.i. was dissolved in water containing $0.02 \%$ Break-Thru and plants were sprayed until runoff. The effects of aviglycine on percentage of natural induction as indicated by a reduction in percentage inflorescence emergence is the primary criterion used to evaluate treatment efficacy. Data on the date and percentage of maximum flowering were also collected and compared with the control treatment.

The percentage flower induction results were subjected to the arcsin transformation and analyzed using SAS ANOVA (SAS Institute, Inc., N.C.) and means were ranked using Fisher's least significant difference test.

\section{Results and Discussion}

Single and double applications of 100 $\mathrm{mg} \cdot \mathrm{L}^{-1}$ aviglycine and single applications of $500 \mathrm{mg} \cdot \mathrm{L}^{-1}$ aviglycine applied over a range of dates had, with one exception, no significant effect or only slightly reduced the percentage of natural induction below that of the control when evaluated on $25 \mathrm{Feb}$. (Table 1). A double application of $100 \mathrm{mg} \cdot \mathrm{L}^{-1}$ aviglycine applied beginning on 9 Nov. reduced natural induction by $11.2 \%$. Double applications of $500 \mathrm{mg} \cdot \mathrm{L}^{-1}$ aviglycine significantly reduced percentage natural induction below that of the control. As with the double application of $100 \mathrm{mg} \cdot \mathrm{L}^{-1}$

Table 1. Beginning date of inflorescence emergence, percentage of plants flowering on 25 Feb., and maximum percentage flowering for different aviglycine (AVG) treatments in the 2001-02 growing season.

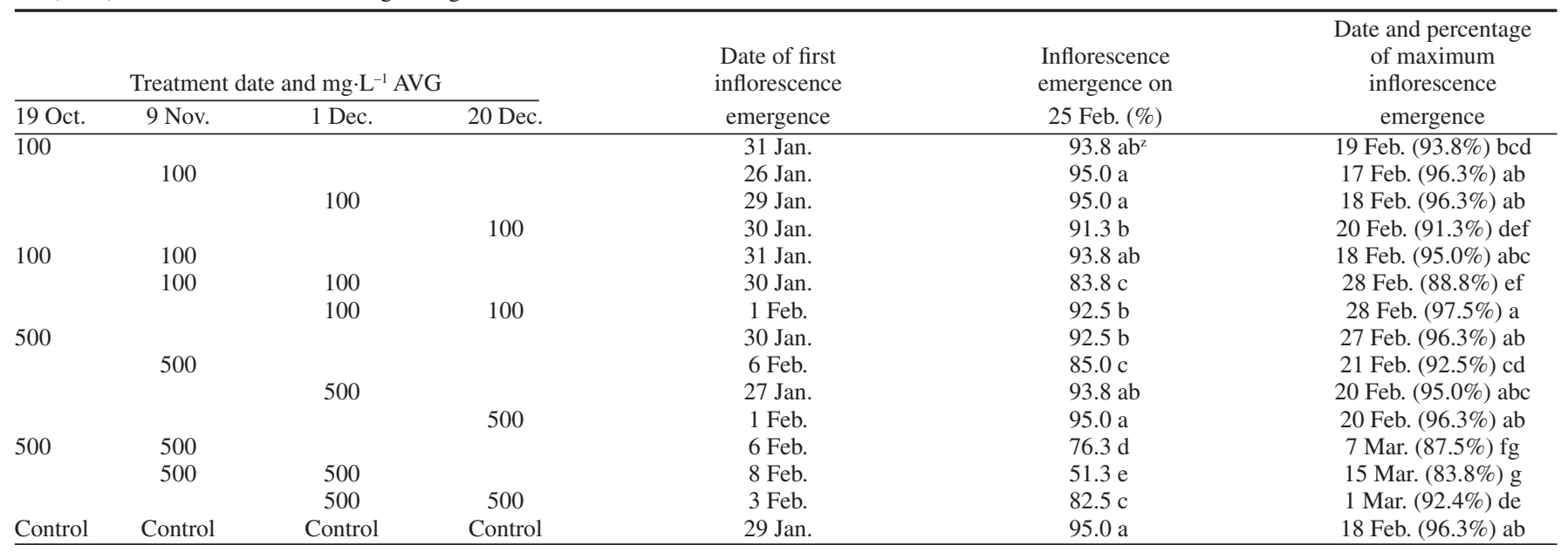

${ }^{2}$ The percentage data were transformed, analyzed, and mean percentages were ranked. Values within a column with the same letter are not significantly different at the $1 \%$ level according to Fisher's least significant difference test.

Table 2. Beginning flowering date, flowering percentage on 28 Mar. and maximum flowering percentage for different quantities of and dates of aviglycine (AVG) treatment in the 2002-03 crop year.

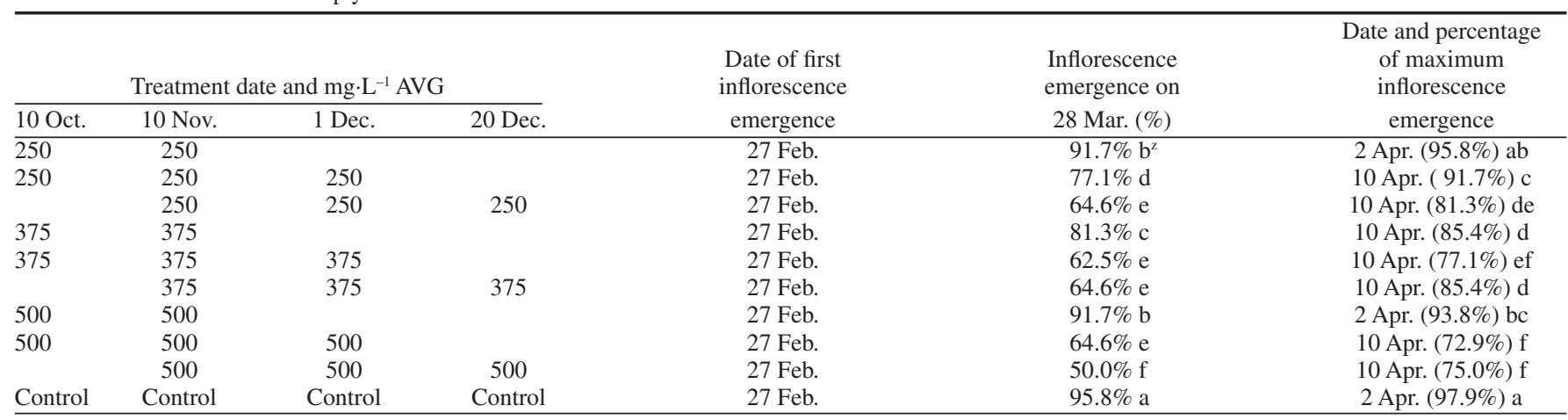

${ }^{2}$ The percentage data were transformed, analyzed, and mean percentages were ranked. Values within a column with the same letter are not significantly different at the $1 \%$ level according to Fisher's least significant difference test. 


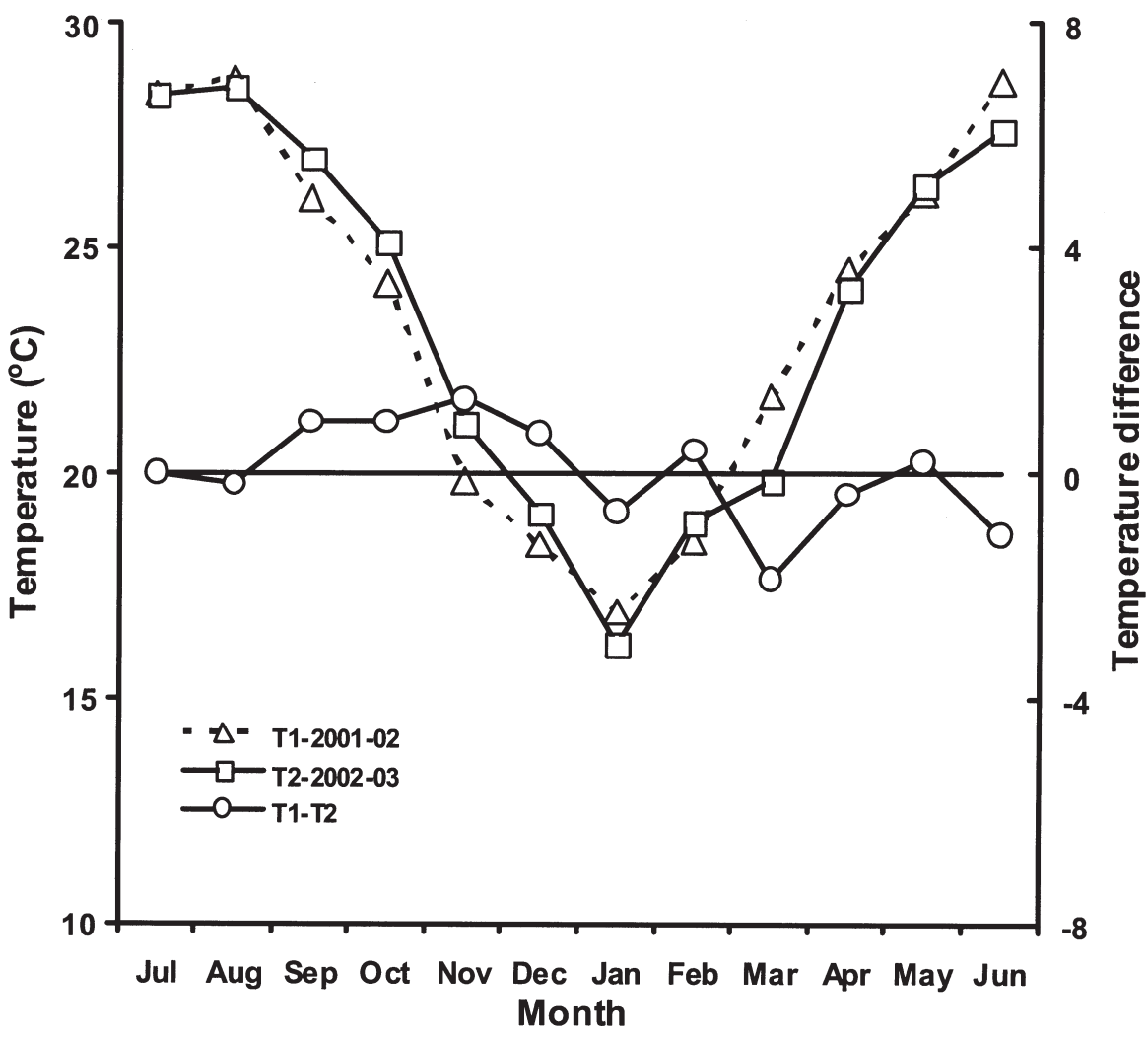

Fig. 1. Mean temperatures for the 2001-02 and 2002-03 crop years and the temperature difference in the 2 years.

aviglycine, the most effective treatment was the one applied beginning 9 Nov. Maximum inflorescence percentage for this treatment evaluated on 7 Mar. also was significantly less than the control. We assume that the 100 $\mathrm{mg} \cdot \mathrm{L}^{-1}$ aviglycine treatments were ineffective or less effective than the $500 \mathrm{mg} \cdot \mathrm{L}^{-1}$ treatments because ethylene production was not inhibited sufficiently by the lower dosage of aviglycine. Aviglycine does not readily penetrate the plant cuticle (G. Venburg, personal communication) and the plant response also appears to be dose-dependent. Thus, we assume that the double application of 100 and $500 \mathrm{mg} \cdot \mathrm{L}^{-1}$ aviglycine treatments applied beginning 9 Nov. significantly reduced natural induction because ethylene production was sufficiently inhibited during a time when natural induction occurred. As noted above, natural flowering is unpredictable and it is assumed that lack of control of natural induction by aviglycine applications made before 9 Nov. as well as those made on or after 1 Dec. resulted from the recovery of ACC synthase activity due to new synthesis of the enzyme before weather events and altered physiology coincided to induce flowering. We also assume that the increase in percentage natural induction for some treatments after 25 Feb. (Table 1) resulted from natural induction that occurred after ACC synthase activity had been restored in plants in those treatments. Since the time from induction to inflorescence emergence for pineapple is about $60 \mathrm{~d}$, i.e., about $60 \mathrm{~d}$ before first appearance of the inflorescences in late January, it seems likely that treatments applied on 20 Dec. were ineffective because natural induction had already occurred.
The significant result obtained in 2001-02 led to the second experiment in the 2002-03 growing season. The $100 \mathrm{mg} \cdot \mathrm{L}^{-1}$ aviglycine treatment was dropped and treatments using 250 and $375 \mathrm{mg} \cdot \mathrm{L}^{-1}$ were added in an attempt to find the most effect as well as the most cost-effective concentration of aviglycine. Treatments that included triple applications of aviglycine were also added to try to extend the duration of control of natural induction. All treatments significantly reduced percentage natural induction below the control when assessed on 28 Mar. (Table 2). However, degree of control varied considerably and triple applications made beginning 10 Nov. provided the greatest control at each concentration of aviglycine. We believe that reduced control was associated with application too long before significant natural induction had occurred and treatments begun on 10 Nov. likely were most effective because the third application of aviglycine extended control of natural induction into mid December when temperatures were cooler and natural induction was more likely. There appeared to be a concentration effect as well because the greatest reduction in natural induction was obtained with 500 $\mathrm{mg} \cdot \mathrm{L}^{-1}$ aviglycine. As with the test conducted in 2001-02, percentage natural induction continued to increase in most treatments well after the end of December, presumably because changes in plant physiology caused additional plants to become susceptible to weather events in January and early February.

Because induction can only be evaluated nondestructively after inflorescence emergence, it was not possible to determine the date(s) of natural induction. The results of the two tests indicate that natural induction did not occur before about 1 Dec. and, in Experiment 1 , had reached about $100 \%$ by late December and probably by $20 \mathrm{Dec}$. This is indicated by the fact that $>90 \%$ of the inflorescences in the control treatment had emerged by 25 Feb., so induction must have occurred 60 or more days before that date. In Experiment 2, the date of $50 \%$ inflorescence emergence was in early March, which was almost a month later than the date of $50 \%$ inflorescence emergence obtained in Experiment 1 (data not shown),. We conclude that induction began later in 2002-03 and probably after 10 Nov. since no control was obtained with treatments applied on 10 Nov. The later date of $50 \%$ inflorescence emergence in 2002-03 also indicates that natural induction continued for a longer period of time in 2002-03 than it did in 2001-02. The average temperature from September through December was warmer in the 2002-03 growing season than it was in 2001-02 growing season (Fig. 1) and we believe it is likely that the delay in natural induction in the 2002-03 growing season was due to the warmer temperatures for that season. The studies of Gowing (1961) and Friend and Lydon (1979) show that reduced temperature is associated with natural induction; however, their data provide no insight into how short-term weather events such as sudden drops in temperature affect natural flowering. It is widely known that natural flowering of a given cultivar is a more serious problem in Australia, South Africa, and Taiwan than it is in Hawaii, presumably because winter temperatures are colder. Natural flowering seldom occurs on well-managed farms in tropical countries such as Thailand (D. Bartholomew, personal communication).

The results of the two experiments in the two growing seasons show that aviglycine can reduce natural induction of flowering of pineapple and that both timing and concentration of the inhibitor are important. While the lowest percentage of natural induction was obtained using $500 \mathrm{mg} \cdot \mathrm{L}^{-1}$ of avglycine, it appears that over the range of concentrations used in the second experiment, timing was more critical than concentration in controlling natural induction of Tainon 18 pineapple. The results with aviglycine indicate that natural ethylene production plays a role in natural flowering. The fact that no treatment completely controlled natural induction suggests that a 20-d application interval is too long to provide complete control because there is sufficient time for ACC synthase to be regenerated, resulting in loss of control.

Timing of aviglycine treatments is viewed as being critical to attaining good control of natural flowering. Where the natural induction period is short, a few treatments with aviglycine may provide complete control, but where natural induction is spread over a longer period of time as it was in the 2002-03 growing season, treatments might need to be continued into January to obtain more complete inhibition. The unpredictable nature of natural induction likely will make complete control both difficult and expensive, especially in Hawaii where winter temperatures are milder 
than they are in Taiwan (D. Bartholomew, personal communication). The difference in dates of maximum natural induction for the two growing seasons indicates a need to better understand the interrelationships between plant physiology and environment to obtain optimum and cost-effective control of natural induction with aviglycine. Aviglycine is the only ethylene inhibitor currently available commercially and registered for use on food crops. We hope that further experimentation will demonstrate the optimum concentration and timing of aviglycine for control of natural induction of pineapple. Further research on the factors that promote natural flowering on pineapple would aid greatly in designing treatments that would provide cost-effective control of natural flowering. Knowledgeable growers of pineapple contend that natural induction is associated with sudden drops in temperature, or the warming of plants after such drops (D. Bartholomew, personal communication). If such is the case, it might be possible to utilize the forecasting of the passage of cold fronts as a guide in applying aviglycine. If aviglycine were applied a few days before such events it might reduce cost and improve control. Such treatments will be a component of future research with this compound. If more complete control of natural flowering could be achieved, it would allow the grower rather than natural factors to determine the date of induction.

Aviglycine inhibits natural flowering of 1year-old Tainon 18 pineapple plants and had no visible adverse effects on the plant or fruit. The threshold concentration of aviglycine for good control of natural induction is $>100 \mathrm{mg} \cdot \mathrm{L}^{-1}$, but may be as low as $250 \mathrm{mg} \cdot \mathrm{L}^{-1}$. Without a better understanding of plant-environment interactions associated with natural induction, multiple applications of aviglycine must be made beginning around 10 Nov. in Taiwan to significantly reduce natural flowering.

\section{Literature Cited}

Bartholomew, D.P., E. Malezieux, G.M. Sanewski, and E. Sinclair. 2003. Inflorescence, and fruit development and yield, p. 167-202, 320. In: D.P. Bartholomew, R. Paull, and K.G. Rohrbach (eds.). The pineapple: Botany, production and uses. CABI Publ., Wallingford, U.K.

Burg, S.P.and E.A. Burg. 1966. Auxin-induced ethylene formation: Its relations to flowering in the pineapple. Science 152:1269.

Chan, Y.K., G. Coppens d'Eeckenbrugge, and G.M. Sanewski. 2003. Breeding and variety improvement, p. 33-55, 320. In: D.P. Bartholomew, R. Paull, and K.G. Rohrbach (eds.). The pineapple: Botany, production and uses. CABI Publ., Wallingford, U.K.

Friend, D.J.C. and J. Lydon. 1979. Effects of daylength on flowering, growth, and CAM of pineapple (Ananas comosus (L.) Merrill). Bot.
Gaz. 140:280-283.

Gowing DP. 1961. Experiments on the photoperiodic response in pineapple. Amer. J. Bot. 48:16-21.

Gowing, D.P.and R.W. Leeper. 1960. Studies on the relation of chemical structure to plant growthregulator activity in the pineapple plant. I. Substituted phenyl and phenoxyalkylcarboxylic acids. Bot. Gaz. 121:143-151.

Mekers, O., M.D. Proft, and L. Jacobs. 1983. Prevention of unwanted flowering of ornamental Bromeliaceae by growth regulating chemicals. Acta Hort. 137:217-223.

Rebolledo, M.A., D.E.A. Uriza, and M.L. Rebolledo. 2000. Rates of fruitone CPA in different applications number during day versus night to flowering inhibition in pineapple. Acta Hort. 529:185-190.

Rebolledo-Martinez, A., D. Uriza-Avila, and L. Aguirre-Gutierrez. 1997. Inhibicion de la floracion de la pina con diferentes dosis de Fruitone CPA en dos dendidades de siembra (Flowering inhibition in pineapple with different rates of Fruitone CPA on two planting densities). Acta Hort. 425:347-354.

Scott, C.H. 1993. The effect of two plant growth regulators on the inhibition of precocious fruiting in pineapple. Acta Hort. 334:77-82.

Van Overbeek J. and H.J. Cruzado. 1948. Note on flower formation in the pineapple induced by low night temperatures. Plant Physiol. 23:282-285.

Yang S.F. and N.E. Hoffman. 1984. Ethylene biosynthesis and its regulation in higher plants. Annu. Rev. Plant Physiol. 35:155-189. 